Sein spec. Gewicht ${ }^{1}$ für die in Betracht kommenden Temperaturgrade, mittelst eines Hirsch'schen Normalaräometers bestimmt, fand ich:

$$
\begin{aligned}
& \text { bei } 10^{\circ} \mathrm{C}=1,155 \\
& -12^{\circ}=1,154 \\
& -14^{\circ}=1,153 \\
& -16^{\circ}=1,152 \\
& -18^{0}=1,151 \\
& -20^{\circ}=1,150 .
\end{aligned}
$$

\title{
Kleine Eisapparate.
}

Von E. Reichardt in Jena.

Von einem befreundeten Collegen wurde ich vor einiger Zeit gebeten, auf dic Einrichtung eines Apparates Rücksicht zu nehmen, welcher in kurzer Zeit kleine Mengen von Eis liefern könne, um bei Mangel desselben und in besonderen Krankheitsfällen das oft sehr starke Bedïrfniss erledigen zu können.

Iierbei ist natürlich von allen den bekannten grösseren Maschinen abzusehen und mehr das Augenmerk auf dic rasche Bereitung einiger hundert Gramme Eis Rücksicht zu nehmen, wozu die sog. Kältemischungen dienen können.

In dieser Beziehung enthielt die Wiener Weltausstellung einen kleinen Schüttelapparat, der Aussteller ist mir augenblicklich nicht bekannt, mit der Einrichtung, dass Kältemischungen in das Innore gegeben wurden und in diese wieder ein kleinerer Apparat, mit Wasser zum Gefrieren versehen. Man empfahl dabei namentlich die Verwendung von salpetersaurem Ammoniak. Das Schütteln mit der Hand war eine sehr lästige, angreifende Arbeit und der Erfolg keineswegs ein sehr ansprechender, desshalb habe ich den

1) Die gelegentlicho frühere Angabe (Arch. d. Pharm. Bd. 212. S. 227. 1878) wurde aus Versehen zu 1,135 statt 1,155 gesetzt, was hiermit berichtigt werden soll. 
Schüttelapparat in eine zu drehende Kaffeetrommel verwandelt, welche zu besserem Schutze doppelte Wandungen hat und in dem Hohlraume schlechte Wärmeleitung, Harz u. dergl. Mitten in der Trommel befindet sich sodann ein hohles Blechgefäss, welches das in Eis zu verwandelnde Wasser aufnehmen soll. Herr Mechaniker Bernh. Pretsch hier hat das Ganze aus starkem Eisenblech sehr haltbar und leicht schliessbar dargestellt und wird bei Bedürfniss den Apparat sehr rasch liefern.

Zunächst mussten aber Versuche angestellt werden, welche Kältemischung sich besser empfehle und wie die Wirkung derselben überhaupt verlaufe!

Es wurden desshalb sowohl mit den bekannten einzelnen Salzen, wie den Salzgemischen Proben ausgefuhrt, auf welche nicht näher eingegangen zu werden brancht, da unbedingt das salpetersaure Ammoniak am raschesten und fast auch am tiefsten die Kältegrade hervorrief. Auch hinsichtlich der Wassermenge wurden Versuche unternommen, jedoch die schon bekannte Erfahrung bestätigt, dass gleiche Gewichtstheile des Salzes und Wassers die besten Verbältnisse sind. Hierbei zeigte sich jedoch, dass wenigstens bei der Lösung in offenen, der warmen Luft ausgesutzten Gefässen die Kälteerzeugung eine sehr rasch anftretende und vorübergehende ist. Die niedrigsten Wärmegrade zeigten sich nach wenigen $4-5$ Minuten, um dann bei 10 Minuten Dauer sofort wieder zu steigen.

Das salpetersaure Ammoniak, als einfach zusammengesetztes Salz, empfiehlt sich aber auch dadurch, dase man dasselbe stets durch Eindunsten der erhaltenen Lösung wieder gewinnt. In der Regel sieht die Lösung nach der Entnahme aus dem Apparate etwas eisenhaltig aus, wesshalb sie filtrirt und dann auf dem Wasserbade wieder völlig eingetrocknet wird.

Da der grösste Kälteeffect von der möglichst schnellen Lösung des Salzes abhängt, ist es nothwendig, das Salz vor dem Einbringen in den Apparat zu pulvern. 
Der Apparat selbst ist nun so eingerichtet, dass sich an der einen Seite eine grosse Oeffnung angebracht befindet, in welche mit grösster Leichtigkeit das Salz und Wasser eingeschüttet werden könneu; man setzt dann vor - oder nachher, nur möglichst schnell, das innere, wasserhaltende Gefäss ein, das Ganze wird sehr einfach durch eine Platte mit Cautschouk dicht verschlossen und ist sofort für die folgende Bewegung im Stande.

Der Apparat, wie ihn Herr Bernh. Pretsch hier auf meine Angaben hin gefertigt hat, soll 20-25 M. kosten und ist dies auch werth. Giebt man in denselben $1 \mathrm{Kg}$. salpeters. Ammoniak und $1 \mathrm{Kg}$. $=1$ Liter Wasser und füllt sodann das Einsatzgefüss mit Wasser von $10-20^{\circ} \mathrm{C}$. (Brunnen- oder destillirtes Wasser), an, schliesst alsbald und leiert 5-10 Minuten, so findet man nach dem Oeffnen circa $250-300 \mathrm{~g}$. festes glasartiges Eis an den inneren Wandungen des Wassergefässes angefroren, während das noch ungefrorene Wasser circa $0^{\circ} \mathrm{C}$. zeigt und somit auch verwendet werden kann. Um das Eis von den Wandungen zu lösen, muss man das Gefäss aussen ein wenig wärmen, durch Eintauchen in heisses Wasser oder einige Minuten warten, wo man alsdann den Eiscylinder ganz heraus ziehen kann.

Bei $2 \mathrm{Kg}$. Salz in 2 Liter Wasser gefroren in $10 \mathrm{Minu}$ ten 640 g. Eis.

Die Versuche verlaufen ebenso glücklich im heissen Sommer, wie im Winter in der warmen Stube, und geben jedenfalls in kürzester Zeit ein sehr gut verwerthbares Resultat.

Da es sich hierbei nur um den Verlust an Salz handelt und die Arbeitskosten des Eindampfens der Lösung, so sind die Kosten entsprechend gering anzuschlagen und bewahrt man das trockene Salz sofort gepulvert in trockenen Flaschen auf, so kann in wenigen Minuten Eis geliefert werden.

Gern bin ich bereit, etwaige Bestellungen zu vermitteln. 